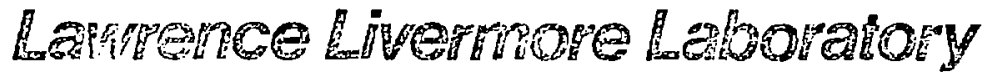

SHIVA ANO ARGUS TARGET DIAGNOSTICS VACUUIA SYSTEMS

S. S. Giaros, S. E. Mayo, D. Campbell and D. Holeman

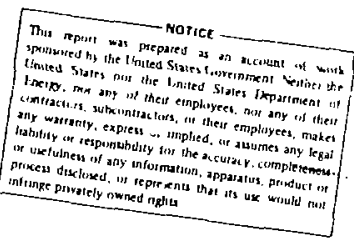

Septeinber 1978

This paper was prepared as an invited paper for the 25 th National Vacuum Symposium - November 27 - Decenber 7, 1978 - San Francisco

This is a preprint of a paper intended for publication in a journal or proccedings. Since changes may be made before publication, this preprifl is made arailable with the undeistanding that it will not be cited or reproduced withou the permission of the autho:

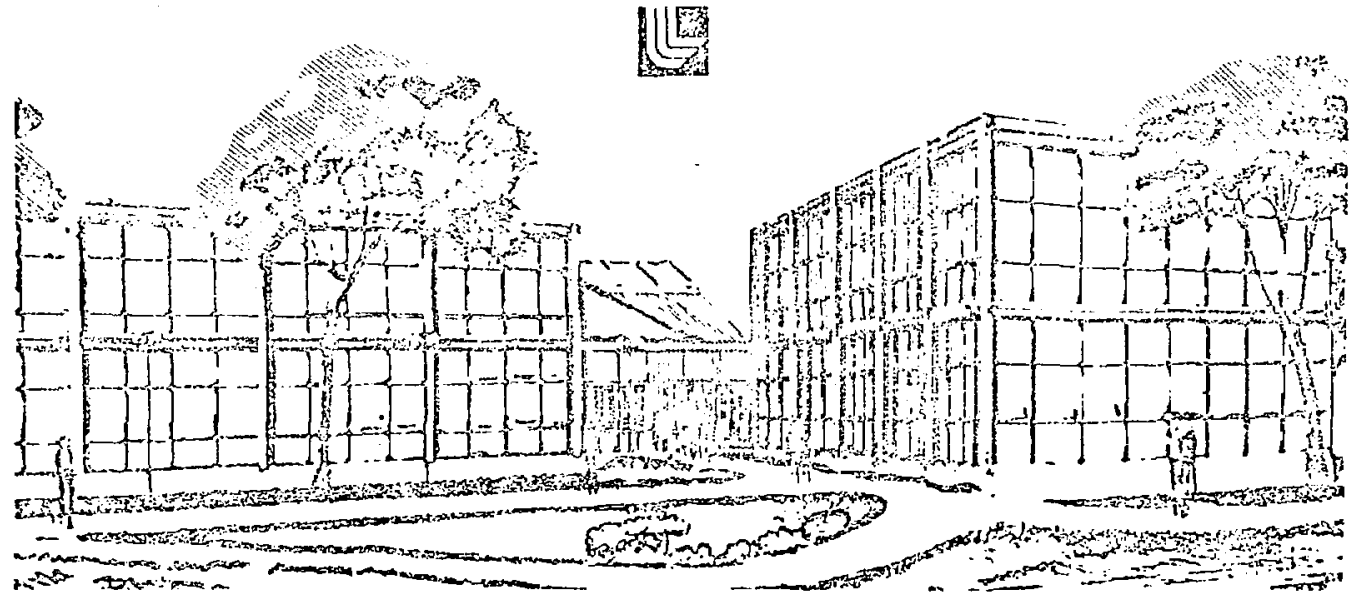




\title{
SHIVA \& ARGUS TARGET DIAGNOSTICS VACUUM SYSTEMS
}

S, S. Glaros, S. E. Mayo, D. Campbel1, \& D. Holeman University of California Lawrence Livermore Laboratory Livermore, California 94550

\begin{abstract}
The normal operation of LLL's Argus and Shiva laser irradiation facilities demand a main vacuum system for the target chamber and a separate local vacuum system for each of the larger appendage diagnostics. This paper will describe the Argus and Shiva main vacuum systems, their respective auxiliary vacuum systems and the individual diagnosics with their respective special vacuum requirements and subsequent vacuum systens. our latest approach to automatic computer-controlled vacuum sysicms will be presented.
\end{abstract}

* Work performed under the auspices of the U.S. Department of Energy under Contract No. W-7405-Eng-48. 


\begin{abstract}
$-2-$
SHIVA AND ARGUS TARGET DIAGNOSTICS VACUUM SYSTEMS

Introduction

The majority of the instruments needed to diagnose laser driven inertialconfinement fusion experiments at Livermore are installed directly on the target chambers. Their vacuum requirements are met by the chamber vacuum systems, which will be described. A number of diagnostics, however, require installation at appreciable distances from the target chambers. This and other considerations dictate the use of auxiliary vacuum systems to attain the desired working pressures. Descriptions of diagnostic vacuum requirements, probiens, and solutions will be presented for the two operational target irradiation facilities: Argus and Shiva.
\end{abstract}

\title{
Argus
}

The Argus target chamber is a cylindrically shaped vessel with a working pressure in the $10^{-5}$ torr range due to frequent cycling and internal diagnostic packages and motorized lens positioners.

The chamber vacuum system schematic (Fig. 1) shows the two independent 17 c:f.m. roughing pumps, either of which can back both high vacuum pumps if necessary. Because the majority of the gas load is from plastic insulation on motors, cables and detectors, tw0 $3100 \mathrm{l} / \mathrm{s} \mathrm{LN}_{2}$ cryopumps are used in series with two $500 \mathrm{l} / \mathrm{s}$ turbollolecular pumps for high vacuum pumping. These high vacuum pumping stations are also independently operable and are coupled to the chamber support tube by low spring constant bellows on opposing ports to minimize vibration and produce zero lateral air pressure loading on the chamber (Fig. 2).

The control panel provides for semi-automatic, relay-logic control of the chamber vacuuln system. The interlock logic sequence is shown in Fig. 3 . This type of control system was chosen because it provides the best combination of simplicity, low cost, flexibility and equipment protection. Under normal operating conditions, the turget chamber can be safely evacuated by a relatively unskilled operator, while the more highly skilled operator can bypass certain interlocks to perform Jeak checking, equipment performance 
tests and troubleshooting.

\section{Argus Auxiliary Vacuum System}

Argus has a separate vacuum system to pump down diagnostics which then operate on their own local system. The system schematic shown in Fig. 4 shows a roughing system backing a $500 \mathrm{i} / \mathrm{s}$ turbo which then is manifolded to the different diagnostics. Each diagnostic has special bypass pneumatic valves which are configured with a small bypass that opens first followed by a settable time lag before the $1 \frac{1}{2} "$ main valve opens. This gradual pumping prevents turbo failures and diagnostic filter damage.

\section{Shiva}

The Shiva target chainber is spherically shaped, about 3000 liters in volume and has over two hundred 0-ring sealed pots. The chamber operated in the $10^{-6}$ torr range with its complement of diagnostics. The vacuum system schematic shown in Fig. 5 is similar to the Argus systern in that the two high vacuum pumping modules are separate from the roughing modules. The high vacuum modules shown in Figs. 6 and 7 are located 11 feet from the chamber and utilize two $15001 \mathrm{iter} / \mathrm{sec}$ turbomolecular pumps in line with the two 3100 liter/sec $\mathrm{LN}_{2}$ cryopumps. The roughing modules shown in Figs. 6 and 8 are located about 40 feet from the chamber and consist of $32 \mathrm{c.f} . \mathrm{m}$. mechanical pumps, $\mathrm{LN}_{2}$ traps to prevent oil backstreaming, arid 164 c.f.m. roots biowers to insure adequate pumping speed at the chamber. In order to prevent fragile and expensive instruinents from being damaged by rapid pressure excursions, both the roughing and vent cycles are arranged so that a low conductance valve opens first, followed (after an adjustaile preset time) by a high conductance valve in parallel with the first.

The Shiva vacuum system control panel, Fig. 9, is similar to the Argus control panel except that all pressure displays are installed in the panel at their appropriate locations. This allows the operator to make a more rapid determination of the system status. The interlock logic sequence is shown in Fic. 10. 
Shiva Auxiliary Vacuum System

Shiva has a separate vacuum system to pump down diagnostics. The system schematic shown in Fig. 12 is nearly identical to the Argus version but does add a two-stage roots $100 \mathrm{cfm}$ blower on the roughing side to provide a higher capacity and lower pressure roughing line to the $500 \mathrm{l} / \mathrm{s}$ turbo. The turbo has a $3100 \mathrm{l} / \mathrm{s} \mathrm{LN}_{2}$ cryopump on top to assist in pumping condensables; this is shown in Fig. 11 along with a portion of the diagnostics vacuum manifold.

Vacion Pumped Diagnostics

A number of the ion diagnostics ard some x-ray diagnostics have small volumes and do not require excessively low pressures, hence were best served by a vacion installation. The pressures achieved without thr vacion addition in some of the longer line of sight diagnostics may rise up to the high $10^{-4}$ torr range.

The Argus alpha spectrometer is pumped with a single vacion after the chamber roughs the spectrometer down to the $10^{-4}$ torr scale. This single vacion maintains the spectrometer at $10^{-5}$ torr. The Argus wideband spectrometers also use one vacion each and achieve the same pressure. The Thompson parabola ion spectrometer uses one vacion along with a roughing line with an isolation value as well as a valve isolating it from the chamber. The Shiva alpha and proson spectrometers shown in Fig. 12 use wo vacion pumps each since they have long line of sights. The Argus $22 x$ and Shiva $8 x x$-ray microscopes use one vacion pump each with an isolation valve in front of the diagnostic.

\section{Turbomolecular Pumped Diagnostics}

The Triplett ion spectrometer is pumped with a separate isolated roughing system as discussed previously and a $500 \mathrm{l} / \mathrm{s}$ turbonolecular pump backed by the previously discussed Argus auxiliary vacuum system. The Triplett is 8 meters long and has a large volume of sandblasted and anodized aluminum tubing providing a high ambient gas load effectively taken care of ori? by a turbo. The isolated system will reach a base pressure of $10^{-6}$ torr and when opened to the chamber, the pressure will rise nearly a decade. 
He Cryopumped Diagnostics

Our most recent series of $x$-ray spectrometers which include the Dante 5 and 10 channel, FFLEX 3 and 20 channel, utilize cryopuming to prevent contamination of very thin foil filters which are x-ray discriminators. A small amount of contamination on the filters requires that the filterdetector system response be recalibrated as a unit. This is expensive and time-consuming. The frequent replacement of these filters due to contamination is also very expensive, hence the requirement for an ultra-clean vacuum system which protects the filters. The Dante series spectrometers utilize $x$-ray diodes operating at $10-20 \mathrm{KV}$ and produce glow discharges at $10^{-4}$ torr or arcing if higher pressure. The local vacuum near the diode had to be kept below $10^{-6}$ torr to prevent photocathode degradation. The photocathode emission is very sensitive to even a monolayer of contaminants. Again, frequent recalibration or cathode replacement are not cost effective but a very !igh vacuum would prevent the need, hence gaseous He cryopumps operating with condensable surfaces down to $10 \mathrm{~K}$ and speeds of up to $1500 \mathrm{l} / \mathrm{s}$ were chosen. The Dunte 10 spectrometer and its cryopump are shown in Fig. 13. The FFLEX 20 channel spectrometer and its cryopuniping system are shown in Fig. 14. The Dante 10 vacuum system schematic shown in Fig. 15 indicates interlocks on the high voltage applied to the detectors being controlled by silicon diode imbeded in the $10^{\circ} \mathrm{K}$ array of the cryopump. The intent is to use the diode signal indicating temperature to turn off the roughing valve at $250^{\circ} \mathrm{K}$ such as to prevent contamination and to turn on the high voltage below $30 \mathrm{~K}$ which insures pressures below $10^{-6}$ torr. The FFLEX vacuum system schematic also shown in Fig. 15 does not require the high voltage interlock since the detectors are not in a vacuuni.

The Shiva FFLEX and Dante 10 crypumping systems are shown connected with the auxiliary vacuum system in Fig. 16. 
Component Evaluation

Most of the major components chosen for the various pumping systems described had been previously used and tested in our program enough so that operating characteristics and pumping speeds were well known. The notable exceptions were the $1500 \mathrm{l} / \mathrm{s}$ turbomolecular pump and three candidate closed cycle He cryopumps.

\section{Turbomolecular Pump}

Time constraints required that this pump be purchased before any sort of comprehensive tests could be performed by us. The decision of which pump to buy was based on cost, estimated turnaround times for repairs, and conversations with manufacturer's representatives and turbopump users. Upon receipt of the pump several weeks were spent familiarizing ourselves with the equipment and performing speed runs to verify the manufacturer's pumping speed data. The equipinent for the speed runs was set up as shown in Fig. 16 . The leak vaive was adjusted to bring the pressure in the dome to the desired point and the pressure drop in the known test volume was measured with an electronic manometer for a given time interval. The throughput thus derived was divided by the pressure in the dome to yield the pumping speed. In order to correct data taken with the ion gauga to a posicion at the pulp inlet, it is necessary to consider the conductance of the dome

$$
C=3.64 \mathrm{KA}(\mathrm{T} / \mathrm{M})^{\frac{1}{2}}=34001 / \mathrm{seC}
$$

The speed of the pump becomes $S_{p}=\frac{S_{A}(-C)}{S_{A}-C}$

The pumping speeds calculated were about 30\% 10:ver than those advertised by the manufacturer despite repiacement of the upper slators in all attempt to improve speed. This sume pump was subsequently retested at the manufacturer's plant using a different dome and two different methods for deternining the throughput: the mass flowmeter method and the burette method. Two ionization gauges were attached to the dome for pressure measurement and gave significantly different readings. Calculated pumping speeds based on the gauge provided by us were generally consistent with those found in previous tests while speeds based on. the gauge provided by the pump manufacturer viere much higher and met the 
pump's specifications.

\section{Cryopumps}

After initial screening, three different models of closed cycle He cryopumps were evaluated to enable us to select the pump most suitable for the various applications previously described. Some of the characteristics considered in arriving at an overall appraisal were: price; punping speed; case of operation; warmup and cool-down times; vibration, noise and heat output of + e compressor. All three units were tested under identical conditions using the same equipment shown in. Fig. 16.

\section{Automatic Control of Ha in and Diagnosi:- Vacuum Systems}

The need for automatic control arose with the increase in the number of separate diagnostic vacuum systems on Shiva. It would be much too timeconsuming to bring up; two alpha spectrometers with two vacions each, three $x$-ray microscopes with one vacion each, up to 4 Dante and 2 FFiEX x-ray spectroneters with one He cryopump each. These 13 pumps presentiy projected for the auxiliary vacuum systom and the main vacuum systcn would consume excessive manpower if not eveistually computer controlled.

The most demanding diagnosic from a control and pressure viewpoint, is the Dante x-ray spectrometer. A probable computer controlled cycle should follow the sequerice below if diagnostic has been cycled to air for filter replacement, the command is pump.

1. Roughing valve is opened remembering that this sequence means voltage is first applied to the bypass $\left(1 / 8^{11}\right)$ solenoid and a finite time later to the $11 / 2$ " valve solenoid.

2. When the dual set point thermocouple gauge senses the pressure is below 1 micron, its relay allows the 6" ASA valve to open, thus allowing the He cryopump to be tirined on.

3. When the cryopump silicon diode temperature sensor tells the dual set point temperature indicator that the head temperature is below $250^{\circ} \mathrm{K}$, its rilay allows the roughing valve to close and prevent any contamination froin the roughing iine. 
4. When the cryopump head reaches $30^{\circ} \mathrm{K}$, the relay closes and turns on the high voltage on the detectors. This temperature insures a pressure below $10^{-6}$ iorr.

5. Computer then interrogates the chamber dual. set point thermocouple gauge and if the chamber is below 1 micron, the computer has a permissive. This now requires another command, open, before the 4" ID bypassed pneumatic can open its small solenoid and a finite time later, the 4" valve solenoid.

The reverse of this sequence is initiated with the command, vent, and is detailed below:

1. If the 4" ID valve has not been closed (close), it is closed now.

2. The 6" ASA valve is closed.

3. The high voltage is turned off.

4. The vent valve has power first applied to the 1/16" valve solenoid, then after a finite time to the 1/2" valve solenoid.

5. When the dual set point thermocouple gauge senses 1 atmosphere, the relay shuts off power to the vent valves, thus preventing any overpressure shock wave later.

The FFLEX $x$-ray spectrometer operates in the same manner even if it does not require the vacuun before the high voltage is turned on since the datectors are outside the vacuum.

The logic sequence used on the $x$-ray microscopes and alpha spectrometers is simpler but the commands are the same. This sequence is detailed below for a system that has been cycled to air, the command is punip.

1. Roughing valve is opened remembering that this sequence means voltage is first applied to the bypass (1/8") solenoid and a finite time later to the $11 / 2^{\prime \prime}$ valve solenoid.

2. When the dual set point senses the pressure is below 1 micron, its relay allows the dual set point digital ion gauge controller to turn on. When 
the dual set point ion gauge controller senses $10^{-4}$ torr or 1ower, it turns on the high voltage to the vacion pumps.

3. The computer then interrogates the chamber dual set point thermocouple gauge and if the chanber is below 1 micron, the computer has a permissive. This now requires another comnand, open, before the $11 / 2 "$ ID valve solenoid can be powered.

The reverse of this sequence is initiated with the command, vent and is detailed below.

1. If the $11 / 2^{\prime \prime}$ ID valve has not been closed (close), it is closed now.

2. The vacion high voitage is turned off.

3. The vent valve has power first applied to the $1 / 16 "$ valve solenoid then after a finite time, to the $1 / 2$ " valve solenoid.

4. When the dual set point thermocouple gauge senses 1 atnosphere, the relay shuts off the power to the vent valves.

The main target chamber will be converted to computer control in the future. If the chamber is at air, the sequence is initiated with the commend pump and is described below:

1. The mechanical pumps are started with all upper valves closed (assumed).

2. When the pressure at TC $3 A$ and $B$ drop back down below 10 Torr, the roots blowers are engaged.

3. When TC $3 A$ and $B$ dual set point thernocouples show 100 microns or less, the relay turns on the automatic $L N_{2}$ trup filler power.

4. The foreline valves V2 A \& B are opened.

5. When TC $2 A$ and $B$ dual set point thernocouple gauges are below 100 microns, the turbo controller power is turred on. At this point power is applied to the automatic $L N_{2}$ cryopump fill system.

6. When the turbo controller interlock relay stating full speed has been achieved, is closed, and the foreline pressure at TC $2 A \& B$ is below $I$ micron the relay al lows $\vee 2 A$ and $B$ foreline valves to close.

7. Power is now applied to the $V 3 A \& B$ roughing valves. The voltage is first applied to the $1 / 8$ " bypass solenoid and a settable tine delay later to the 4" ID valve solenoid. 
8. When TC 1 reads below 50 microns, the relay turns off $V 3 A \& B$ roughing valves, opens $V 2 A$ \& $B$ foreline valves and then opens $V 1 A \& B$ main 6" ASA high vacuurn valves.

9. When TC 1 thermocouple drops below 1 micron, it turns on the extended range ion gauge IGI, dual set point controller. 


\section{ACKNOWLEDCEMENIS}

The authors wish to thank $H$. Patton for his consultation and G. Still for his consultation and performance calculations. We would like to thank 0 . Puckett for his numerous hours in conducting pump speed runs. We also would like to thank $M$. Crowninghield for his design of the computer logic circuitry.

Reference to a company or product name docs not iniply approval or recommendation of the product by the University of California or the U.S. Department of Eirtergy to the exclusion of others that may be suitable.

NOIJC:

"This report was prepared is ar acentur! of work Sponsnred by the Libied Siates Governmient. Deparimste of Enerey, ror ary of their emed States nor any of their eound inores. their cniployes contrisclois, subiontractors. of their cmployees. makes any wirranty, cxpress or implicd, or assumes any tegal liainity, express or sibility for the accuracy compietenesson. usefulness of any inforniation, appar:Ius, product or proc:ss disclosed, or represenis that its wse would nol infringe privatcly-ouned rights." 


\section{LIST OF FIGURES}

Figure 1

Figure 2

Figure 3

Figure 4

Figure 5

Figure 6

Figure 7

Figure 8

Figure 9

Figure 10

Figure 11

Figure 12

Figure 13

Figure 14

Figure 15

Figure 16

Figure 17
Argus Target Chamber Vacuum System Schematic

Argus Target Chamber Vacuum System

Argus Target Chamber Vacuum System Interlock Logic

Argus Auxiliary Vacuum System. Schematic

Shiva Target Chamber Vacuum System Schematic

Shiva Target Chamber Vacuum System

Shiva High Vacuum Module

Shiva Roughing Vacuum Module

Shiva Target Chamber Vacuun System Control Pane]

Shiva Target Chamber Vacuum System Interlock Logic

Shiva Auxiliary Vacuum System Schematic

Shiva Alpha Spectromecer

Dante 10 Channel $X$-Ray Spectrometer

FFLEX 20 Channel $X$-Ray Spectrometer

Dante 10 and FFLEX Vacuum system Schematic

Shiva Diagnostics Vacuum Systems

Turbomolecular and Cryo Pump Test Setup 
ARGUS VACUUM SYSTEM

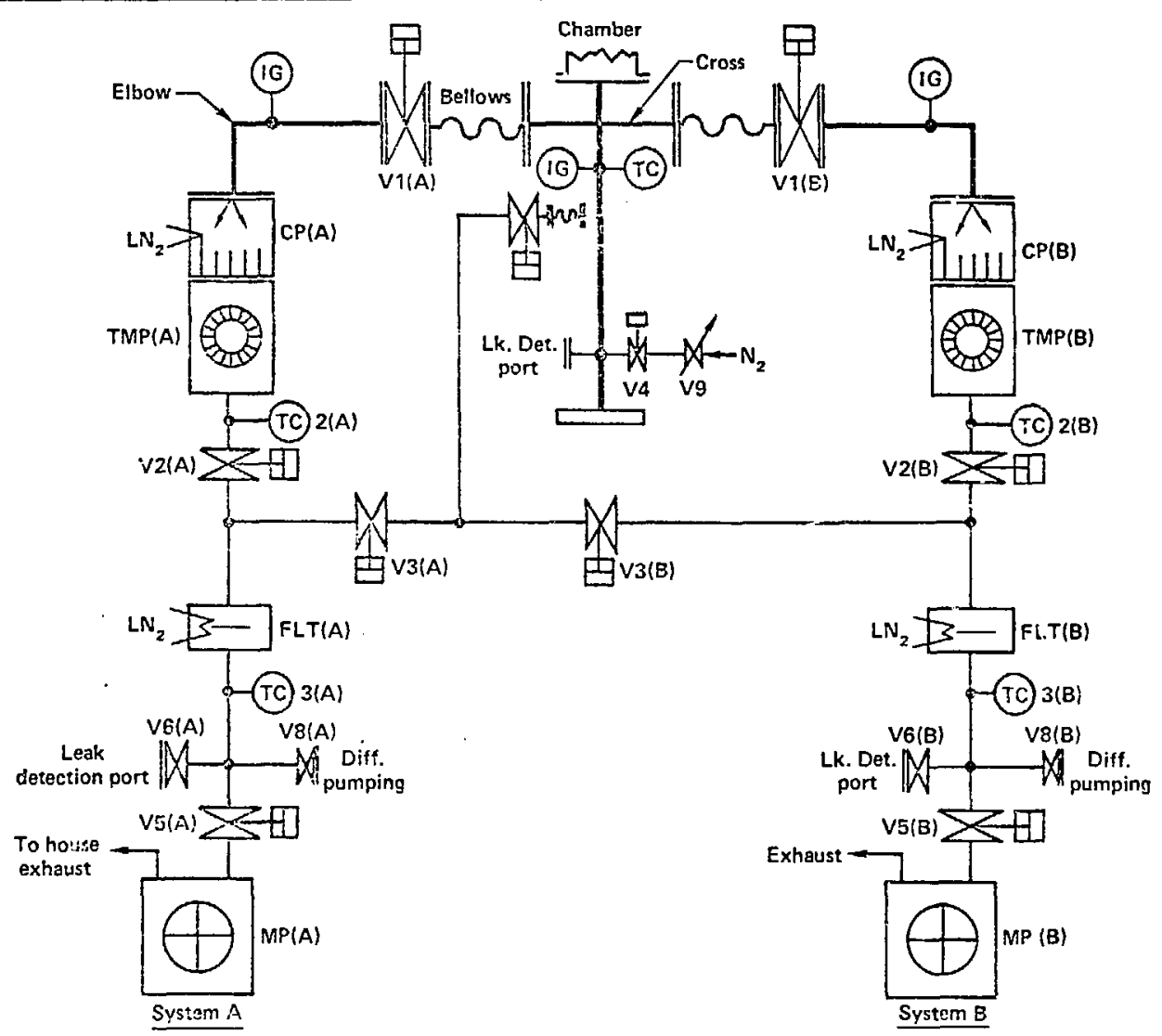

FIGURE 1 

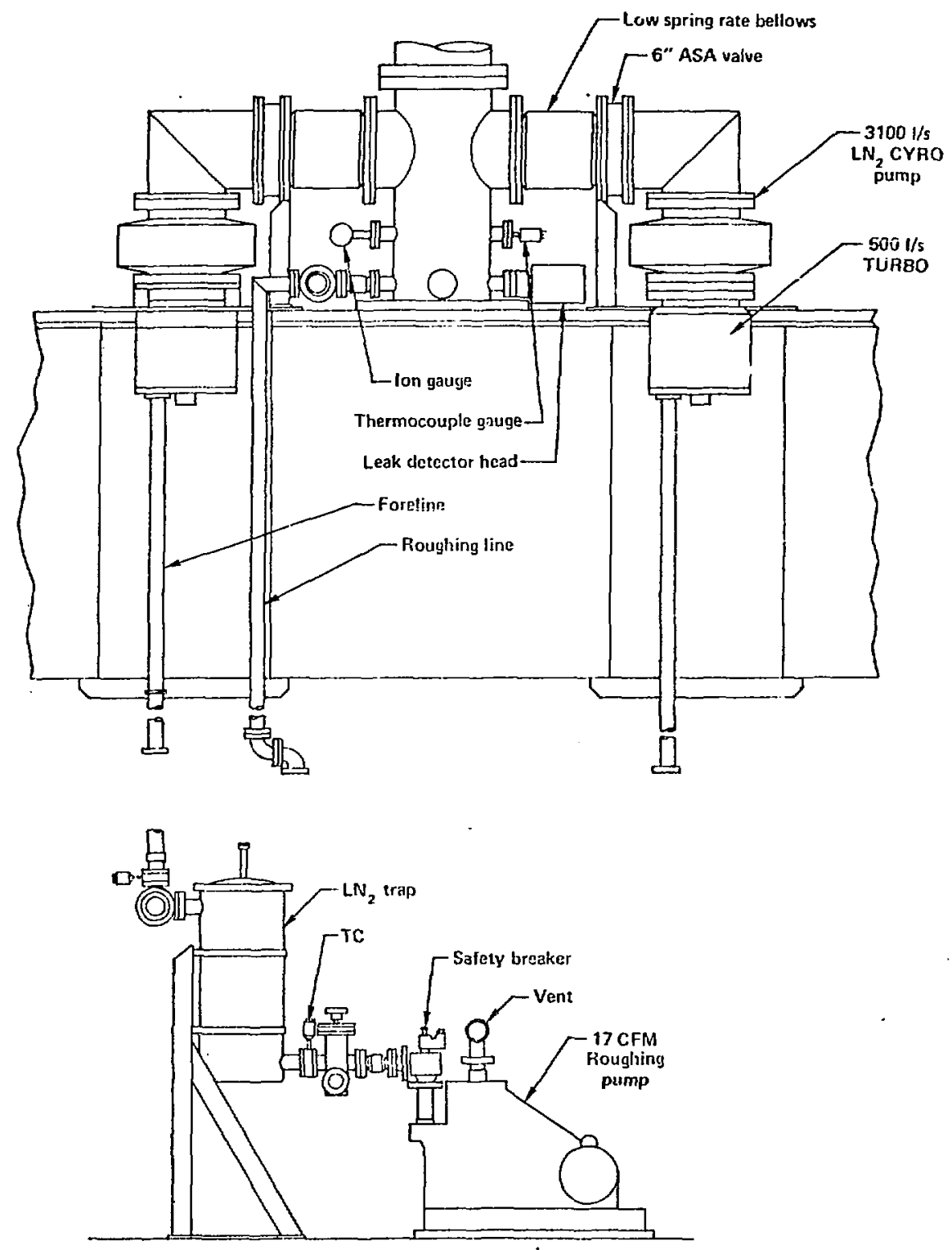

FIGURE 2 


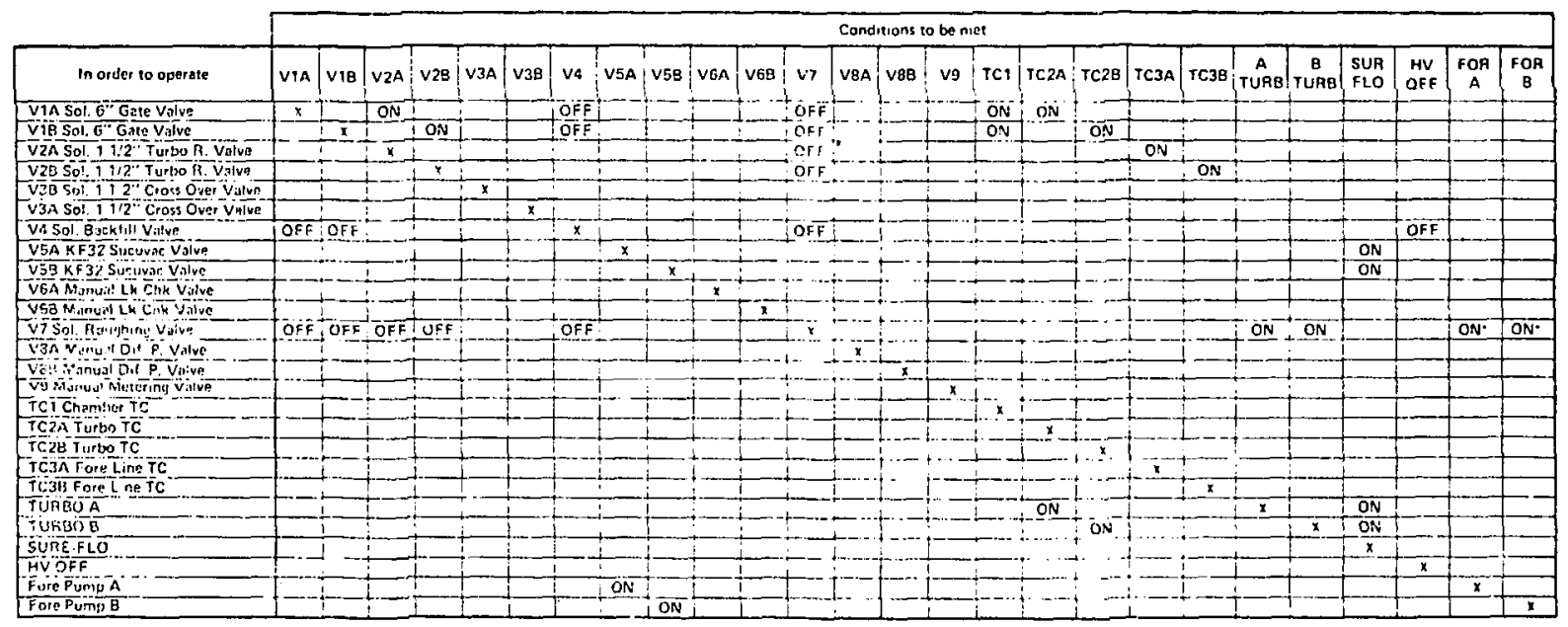

- Either roughing punip

FIGURE 3 


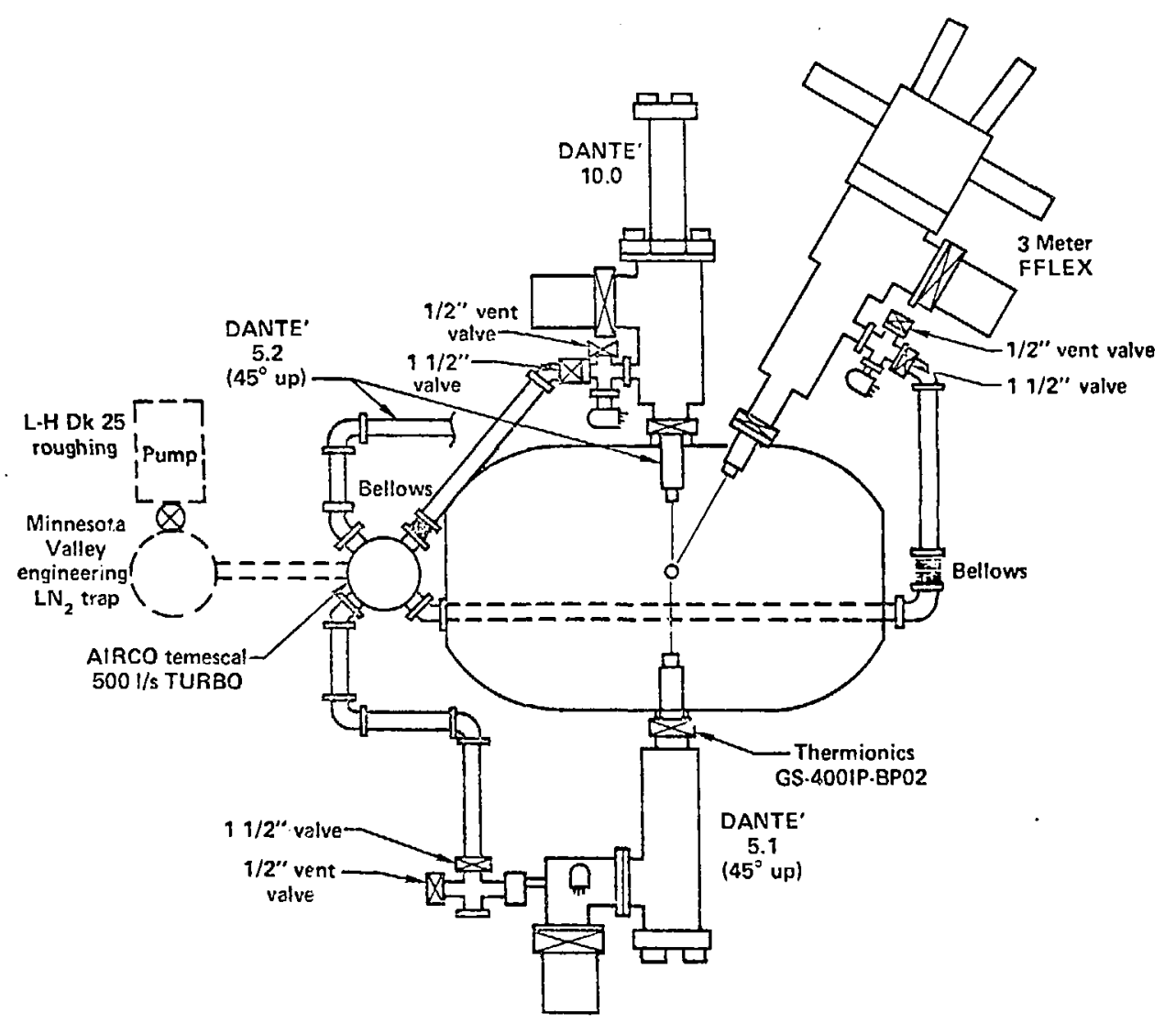

FIGURE 4 


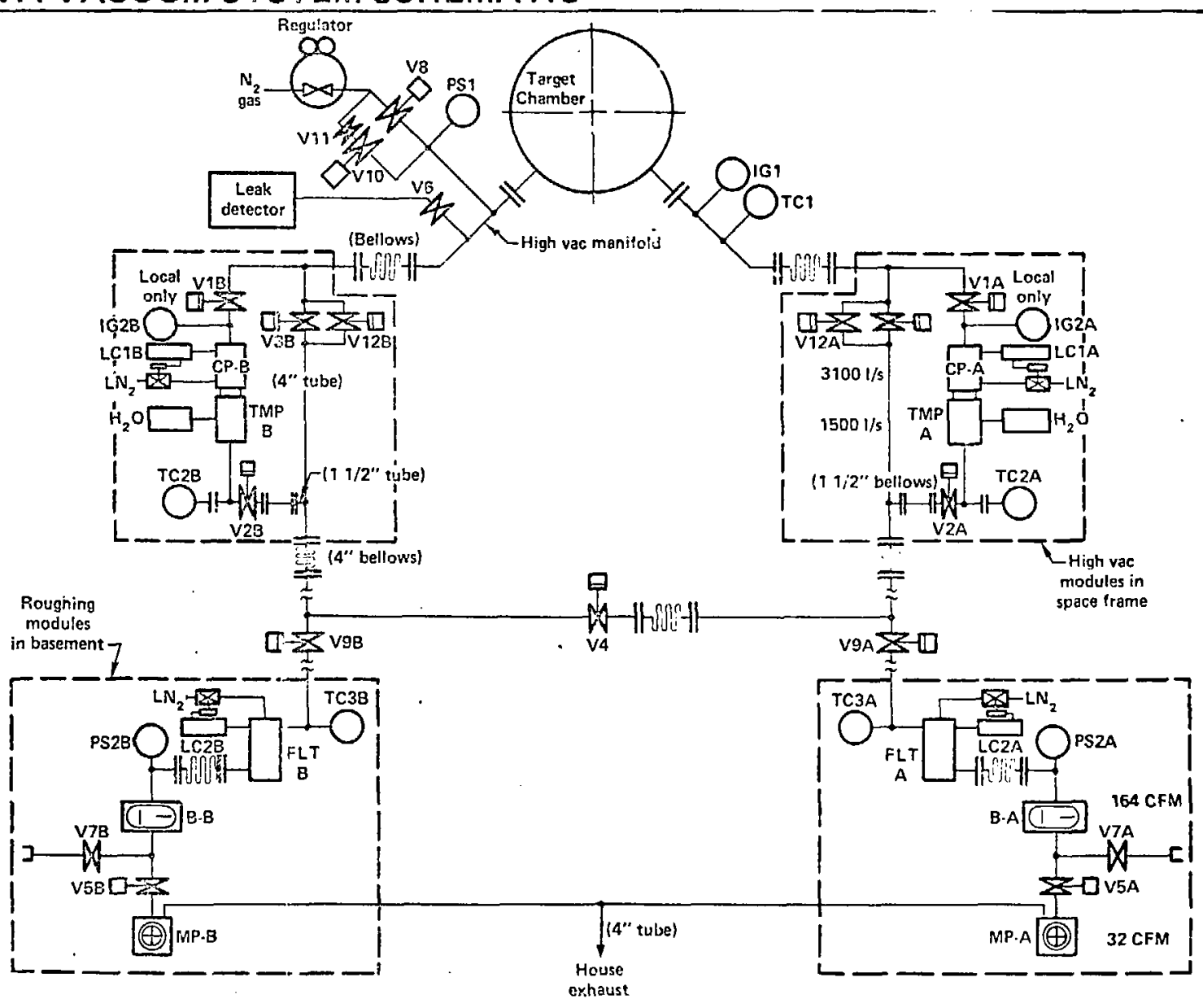

FIGURE 5 

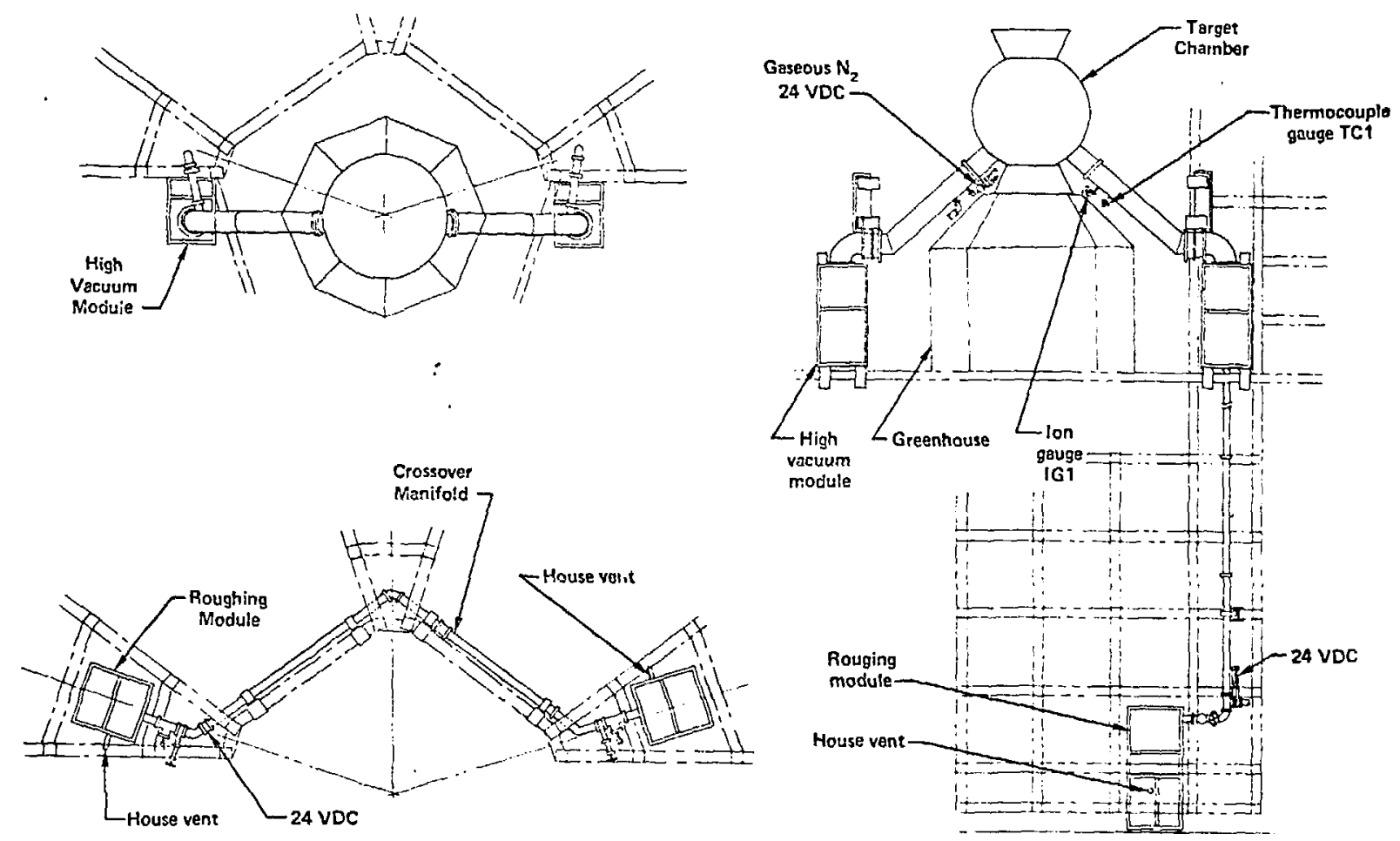

FIGURE 6 

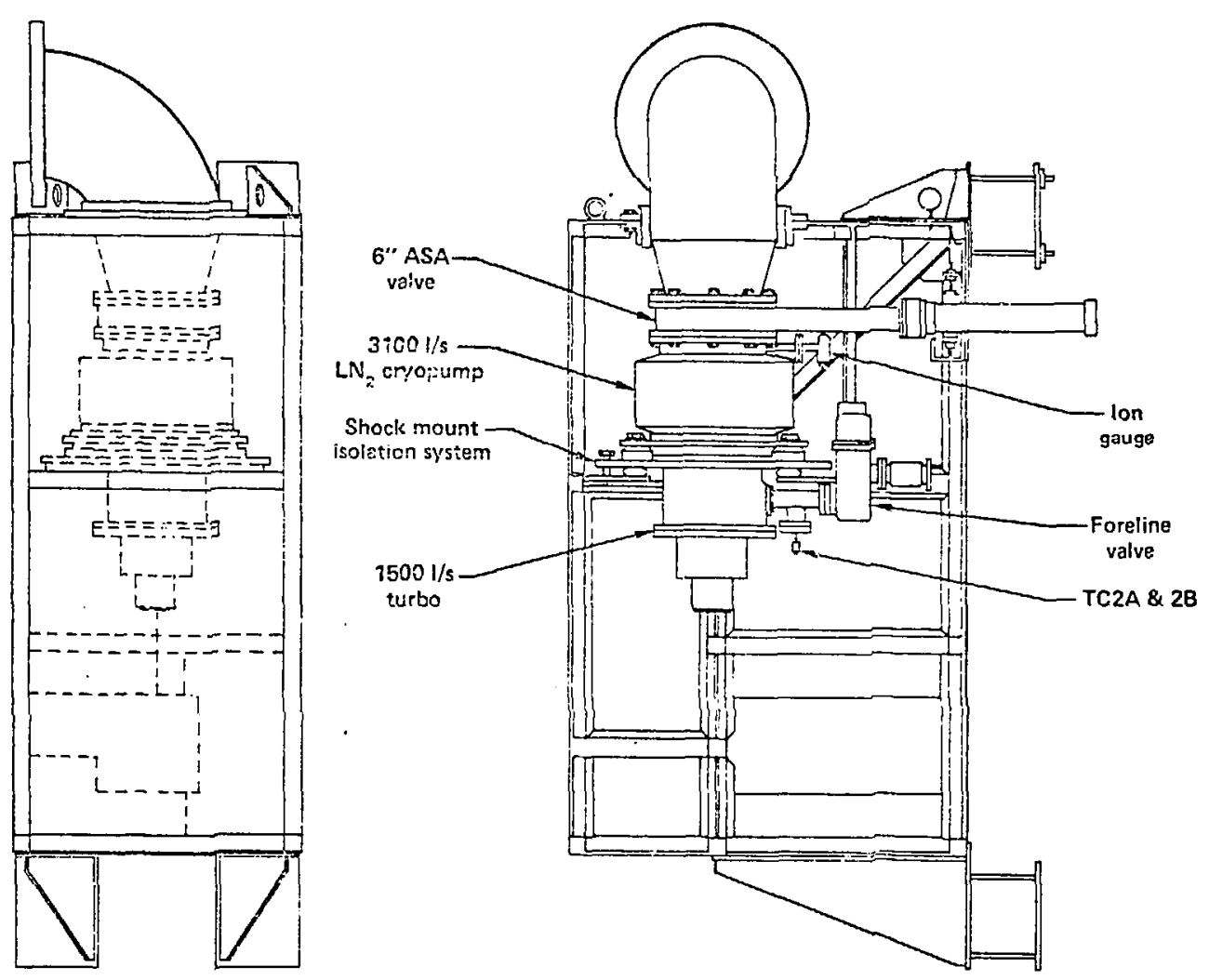

FIGURE 7 
SHIVA ROUGHING MODULE

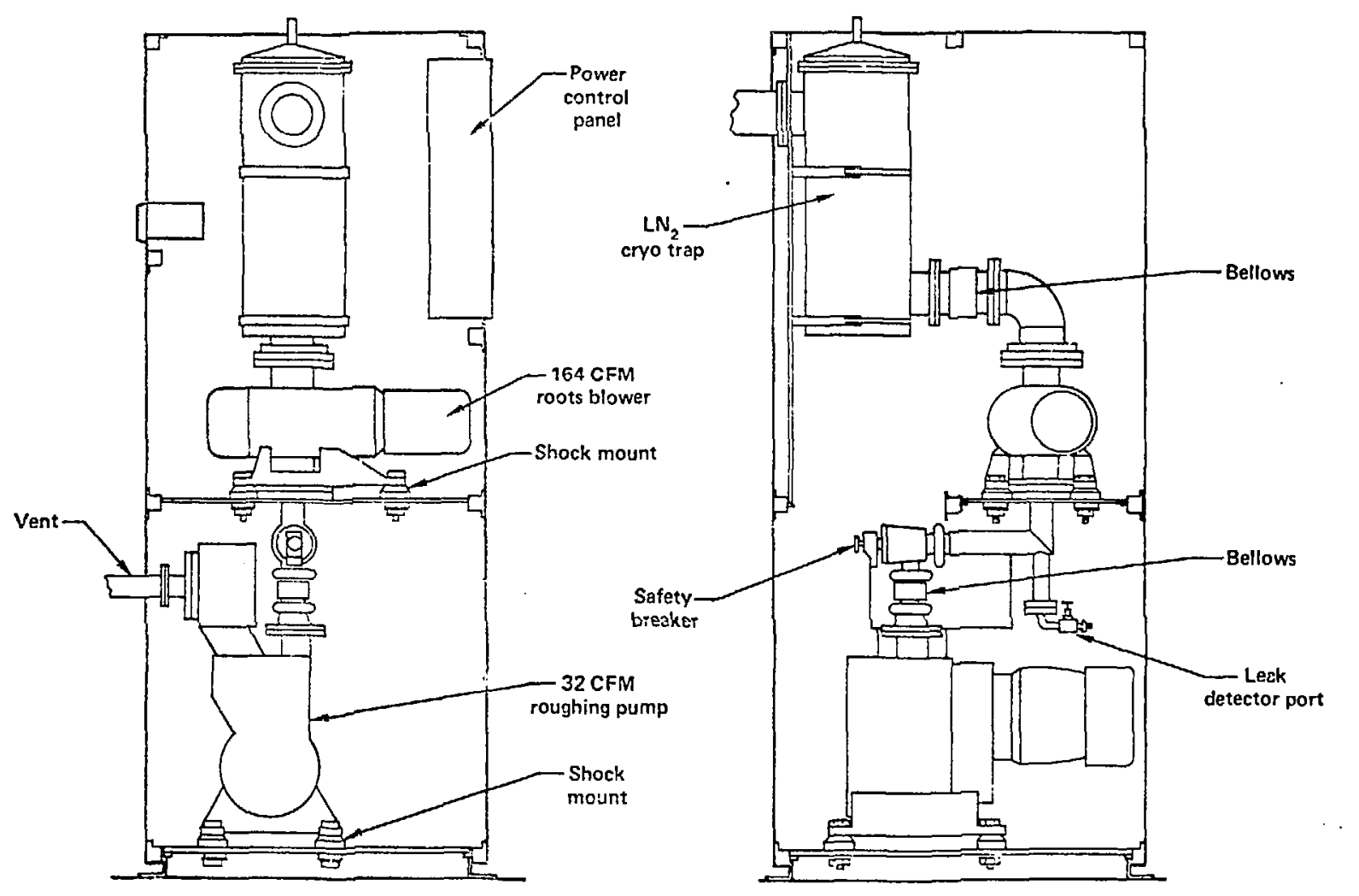

FIGURE 8 


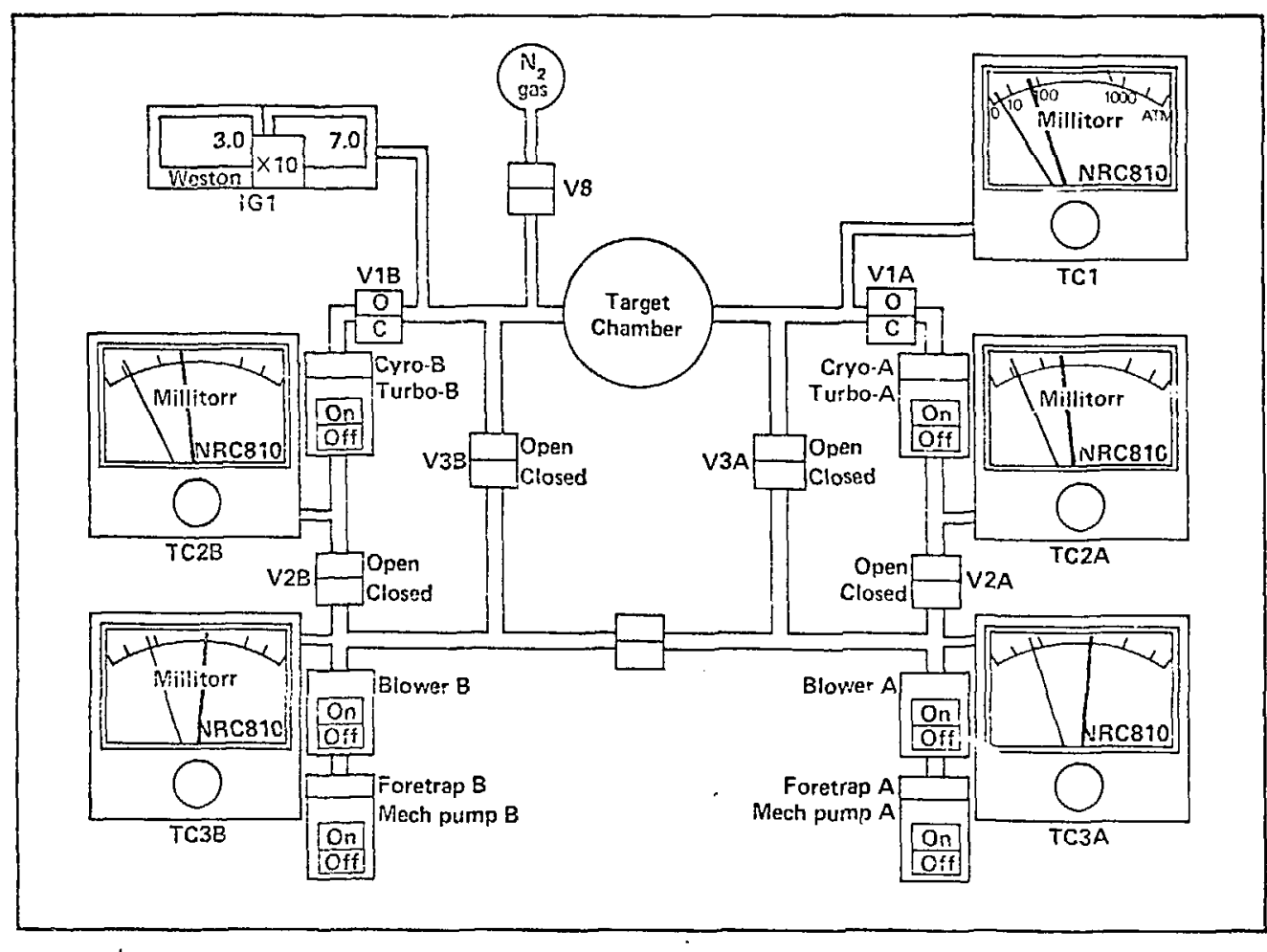

FIGURE 9 


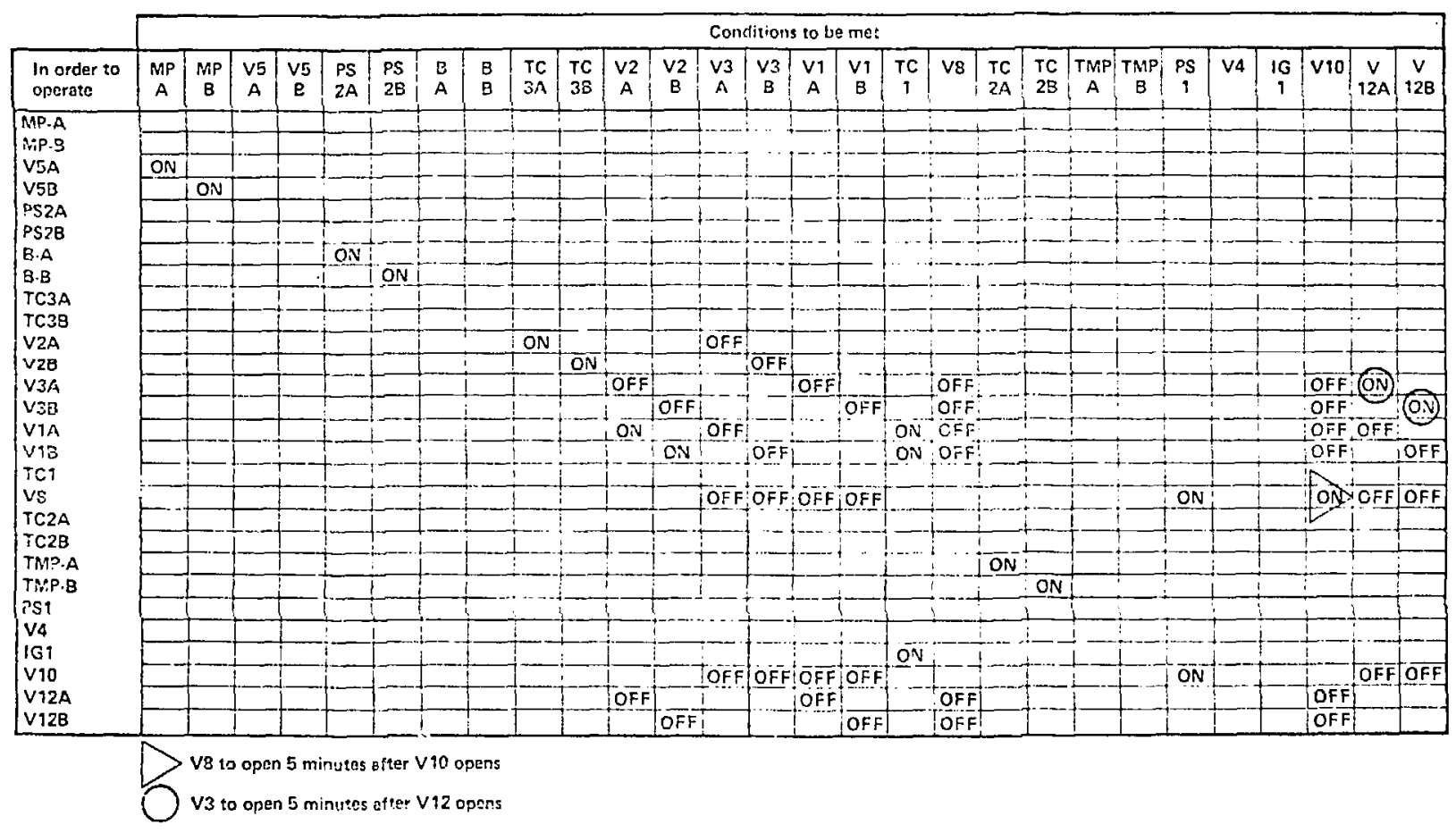

FIGURE 10 


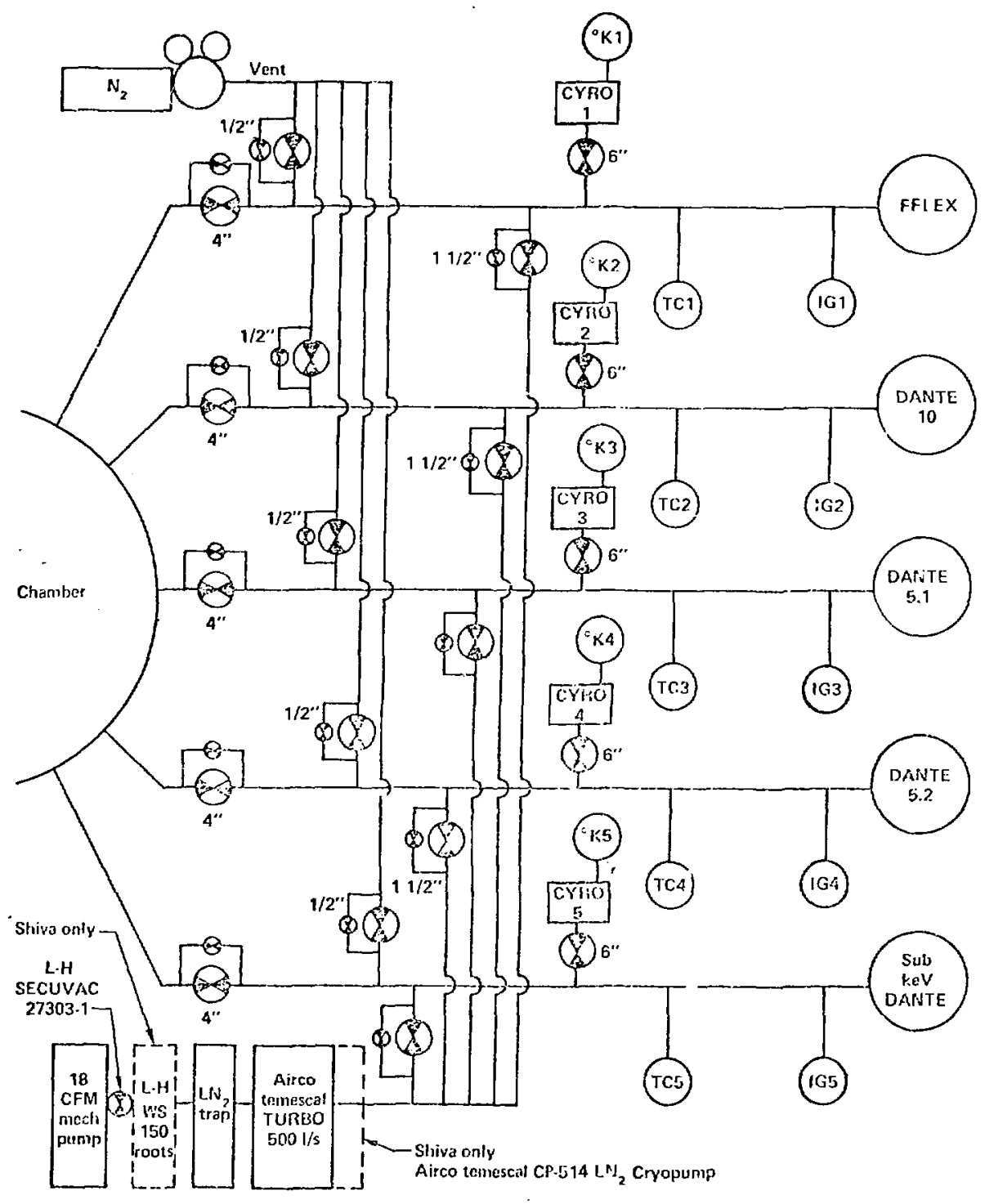

FIGURE 11 

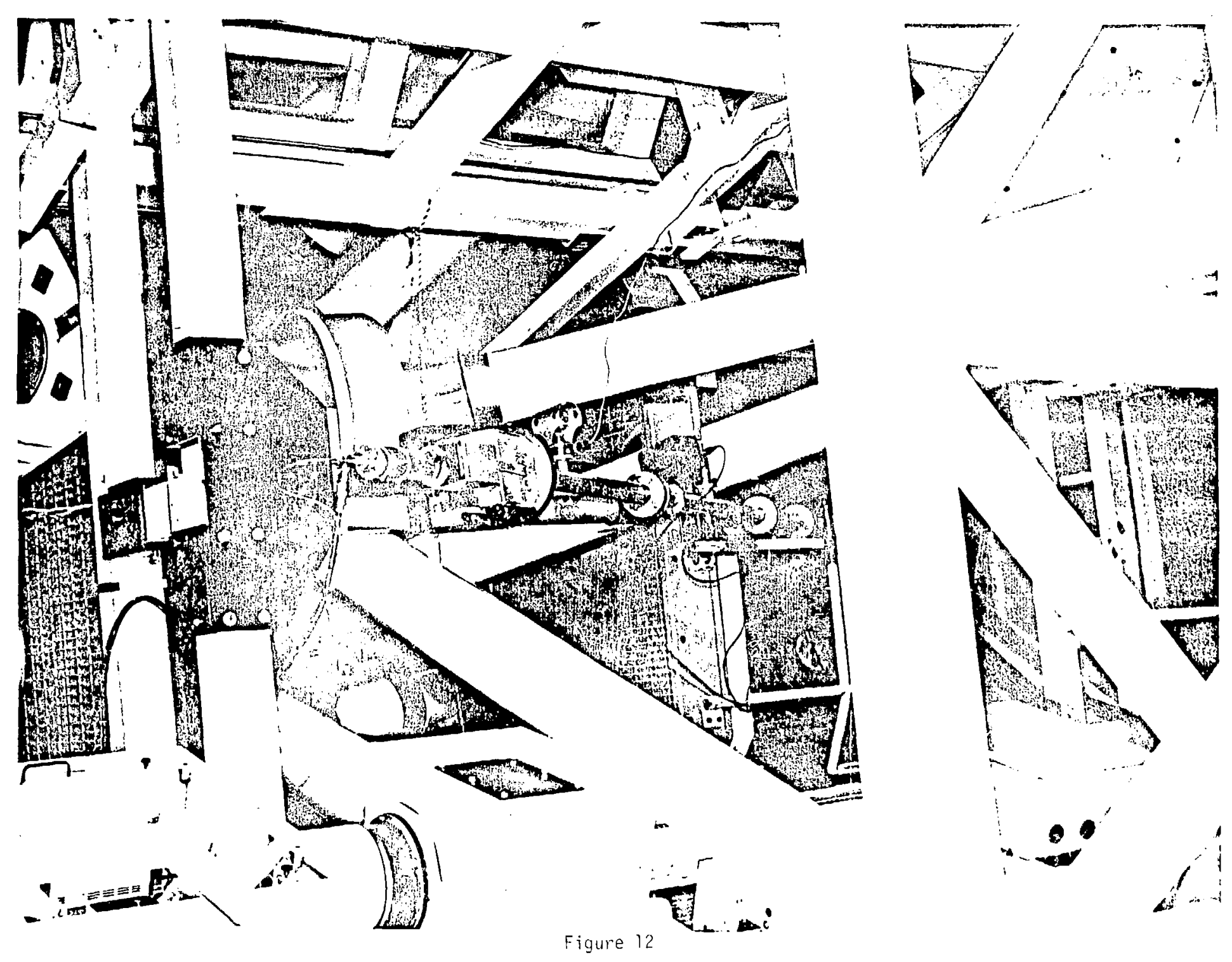

$==$ 


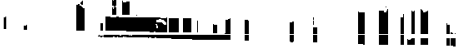
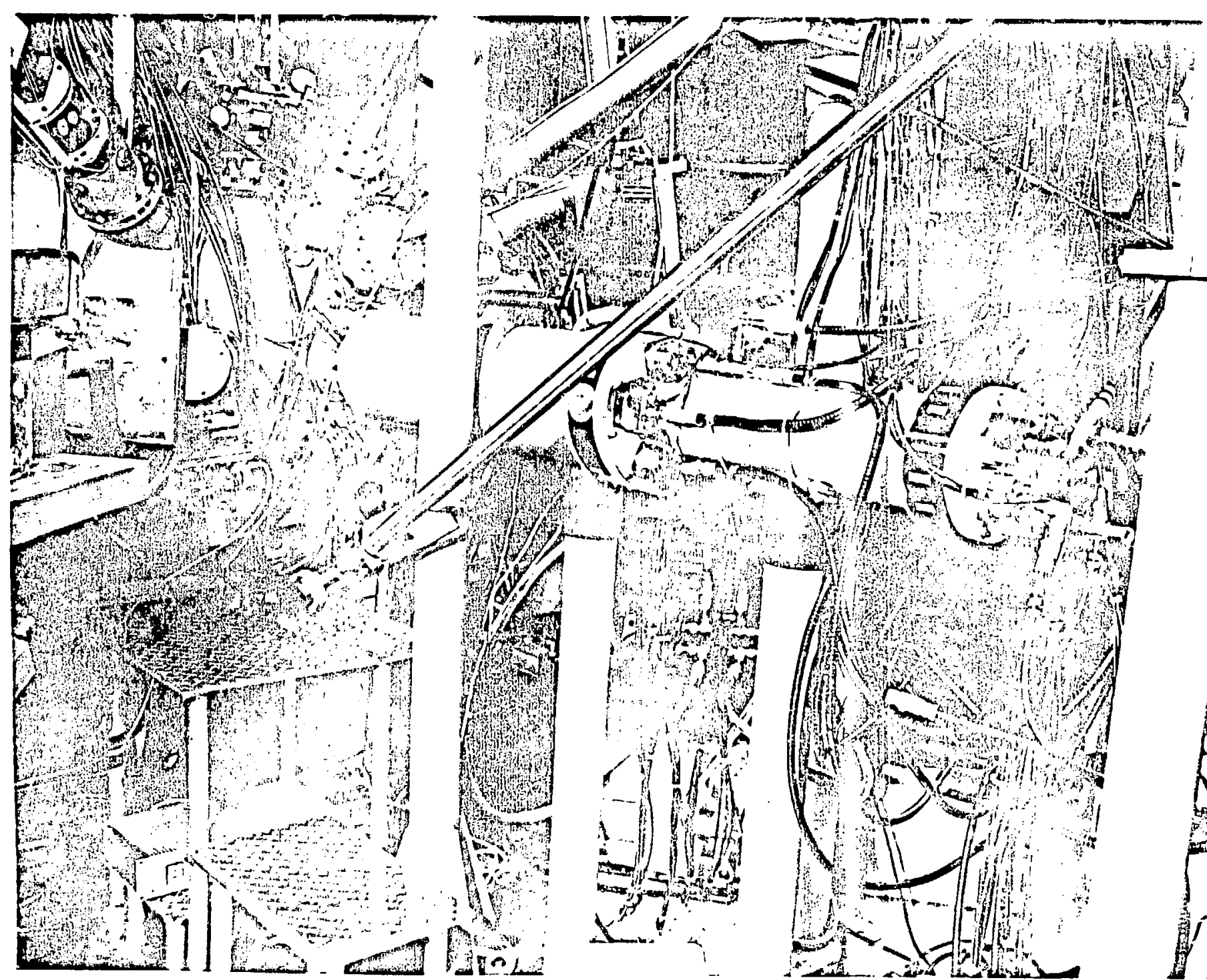

(1) ato
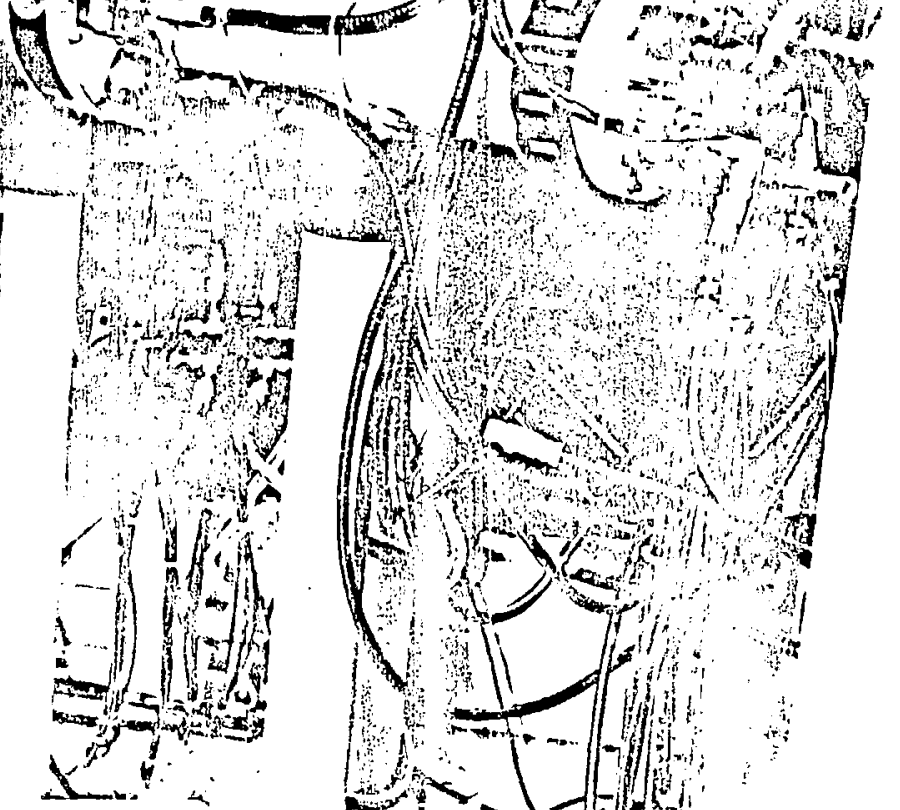

$$
7 \text { (1) }
$$

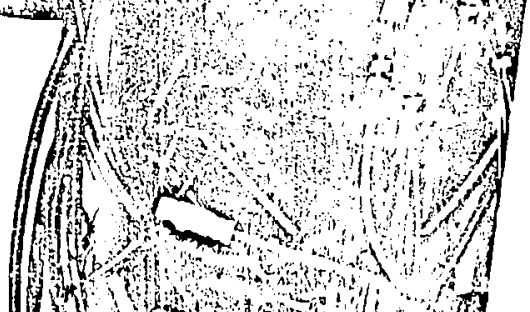

(192)

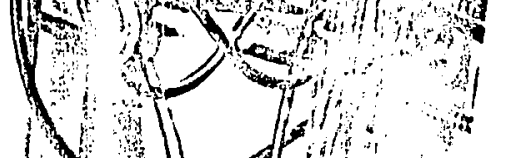

A.

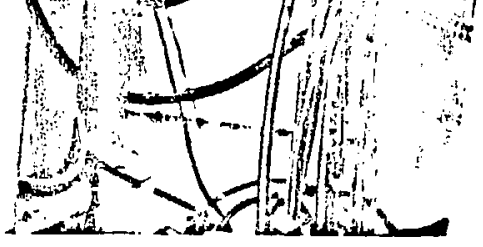

Figure 13

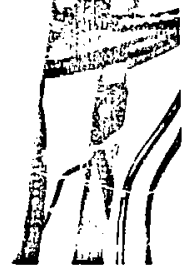




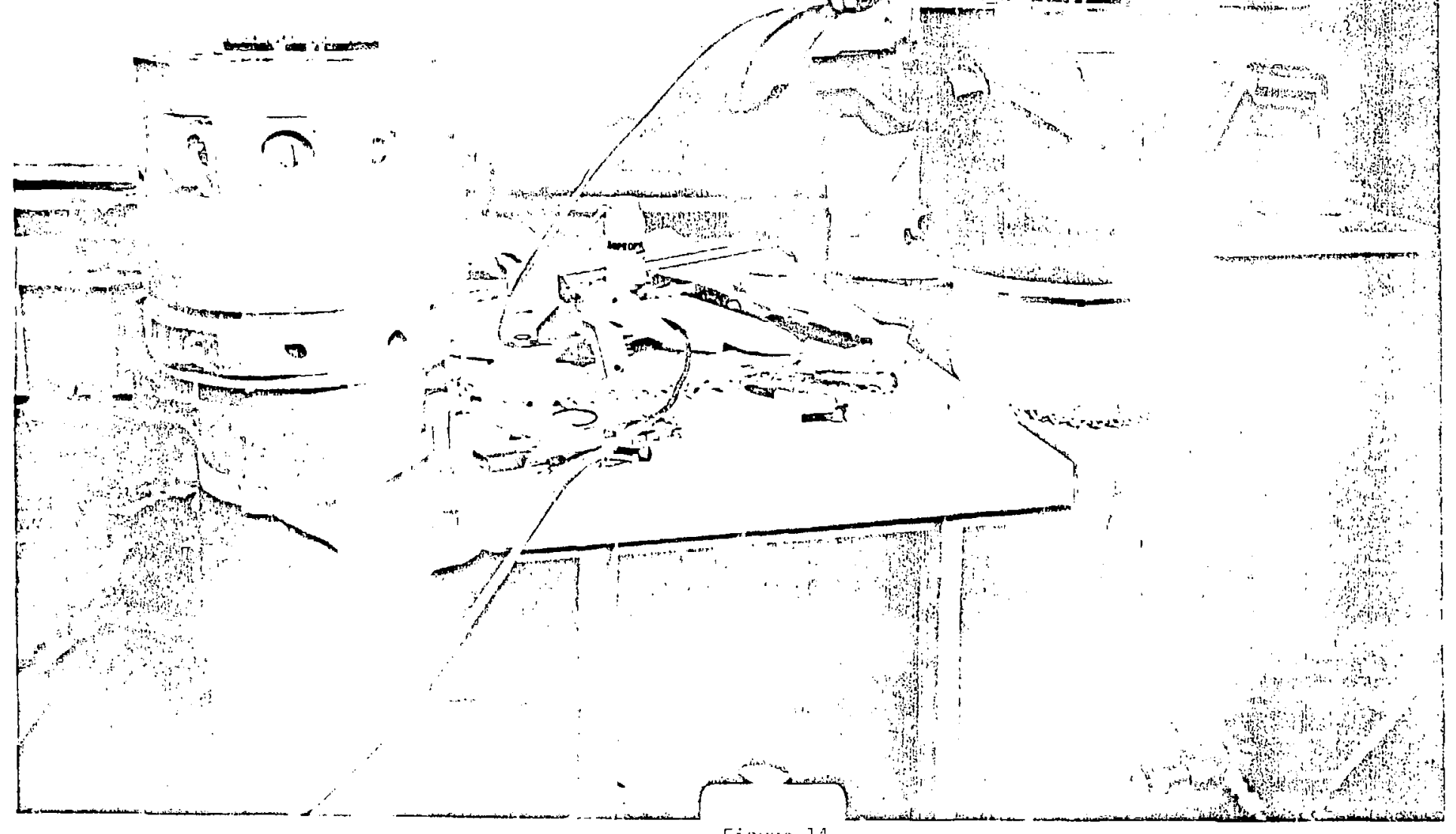

Figure 14 
DANTE 5

DANTE 10

FFLEX

Sub keV DANTE

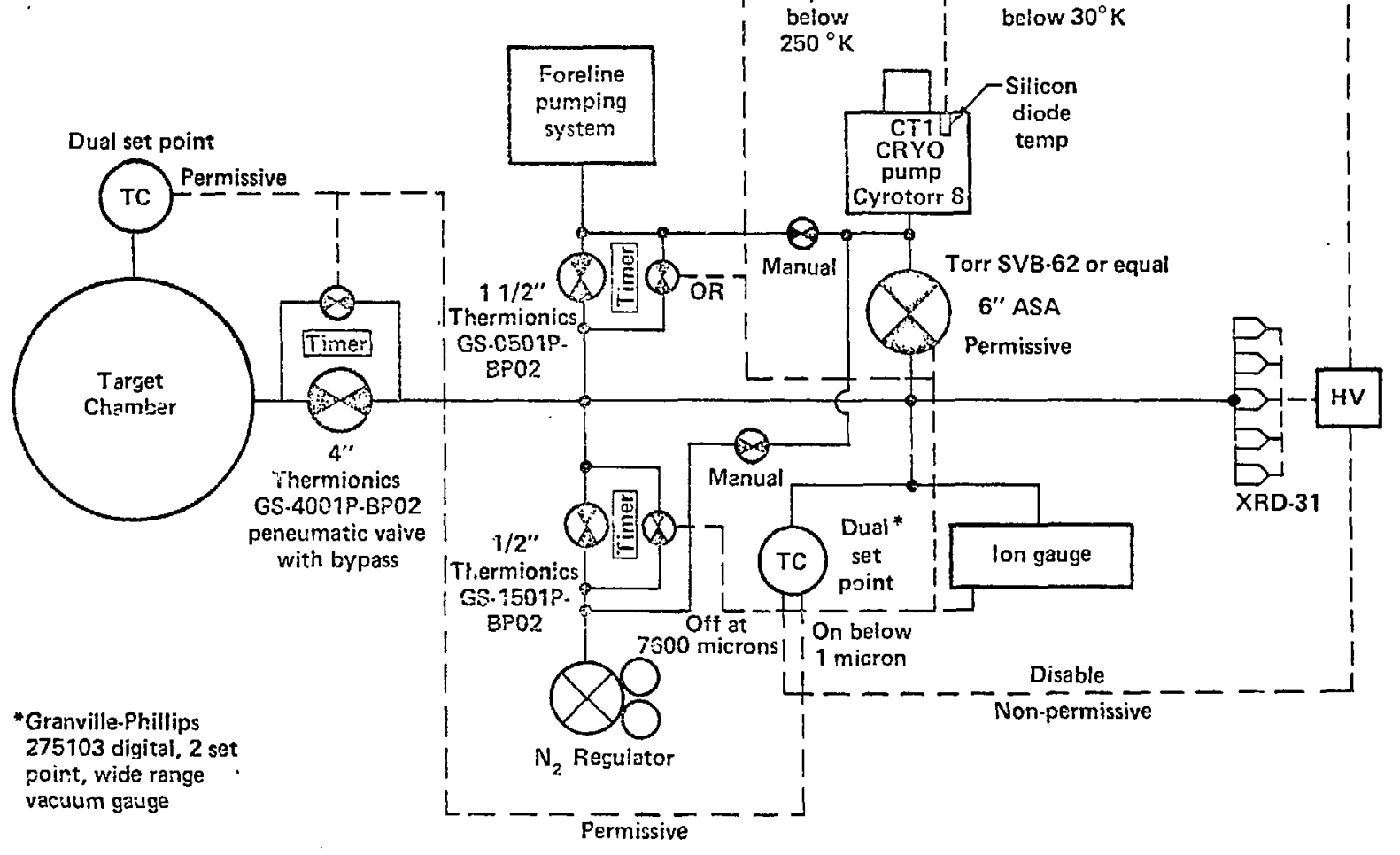

$11 /$ temp indic.

Enable

Elosed circuit - - -

Circuit Plosed circuit

below below $30^{\circ} \mathrm{K}$

$\square$ 'Silicon

CRYO temp

Torr SVB.62 or equal

Dual set

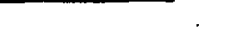




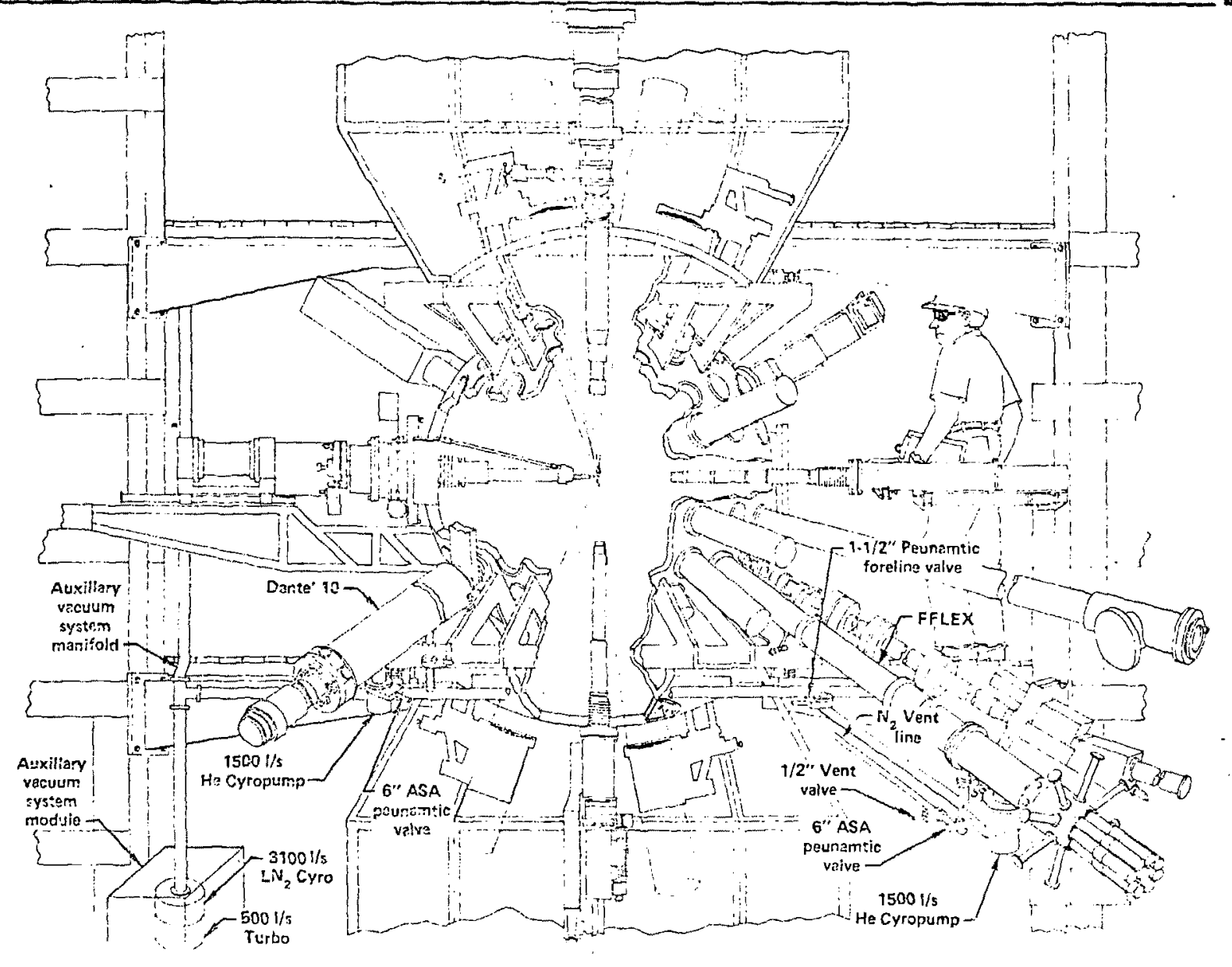




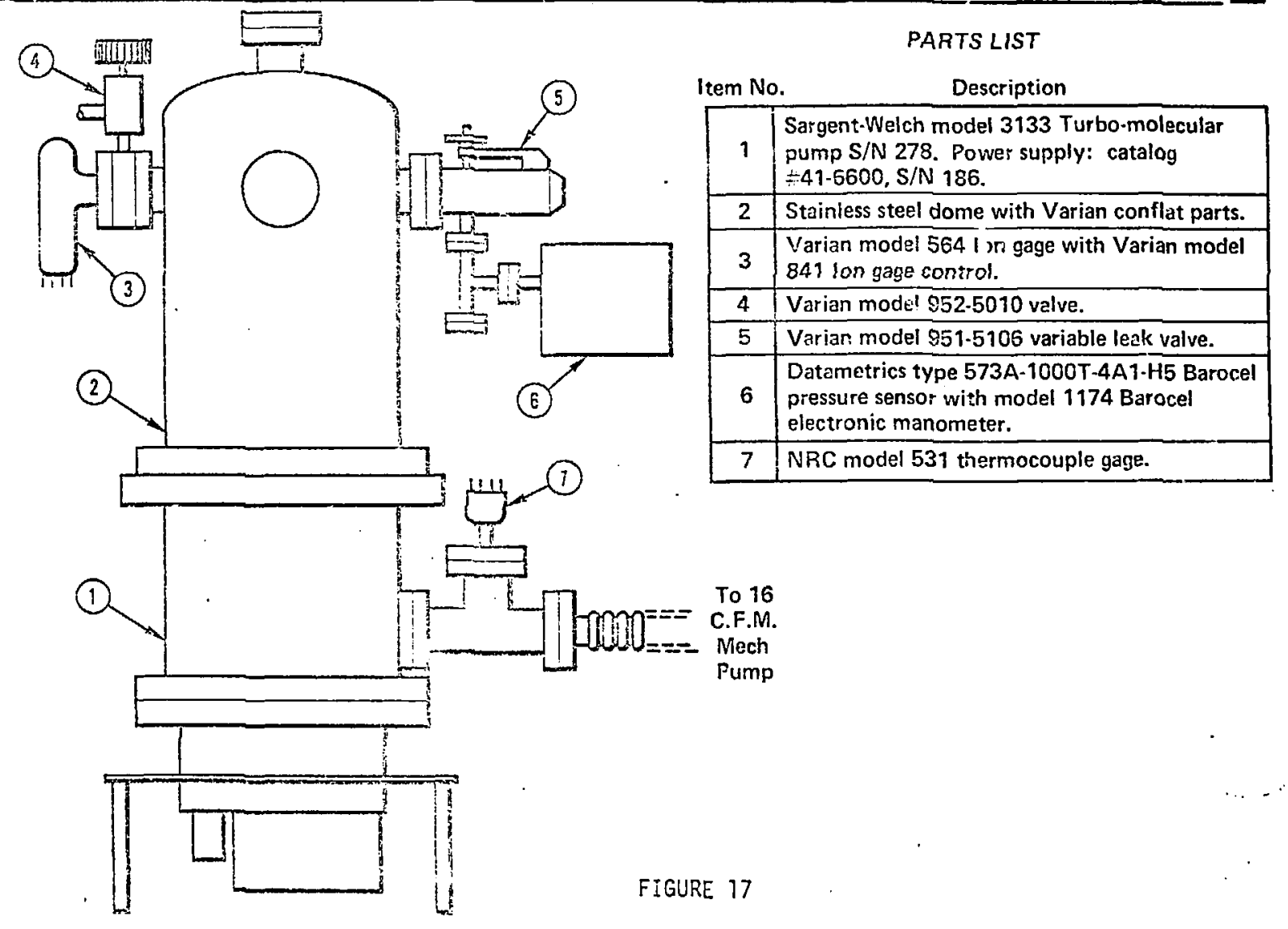

